\title{
Projetos de veículos automotores: fatores críticos de sucesso no lançamento
}

\author{
Heitor Luiz Murat de Meirelles Quintella, D.Sc. \\ Henrique Martins Rocha, M.Sc. \\ Manuela Fontana Alves \\ Universidade Federal Fluminense
}

\begin{abstract}
Resumo
A identificação dos chamados fatores críticos de sucesso no lançamento de veículos automotores é extremamente importante ainda na fase de desenvolvimento do projeto. Nesse sentido, o objetivo deste estudo foi validar os fatores identificados pelos prognósticos de Porter para o lançamento de novos produtos e/ou pelos estudos de Daniel e Rockart na indústria automobilística americana entre os anos 1960 e 1980. Como referenciais teóricos foram utilizados os fatores críticos de sucesso de Rockart e o modelo de ciclo de vida de Porter. Partindo da literatura existente sobre o assunto e das deduções via prognósticos, foram identificados e validados, através de pesquisa de campo em duas montadoras instaladas na região Sul Fluminense do País, cinco fatores críticos de sucesso.
\end{abstract}

\section{Palavras-chave}

Fatores críticos de sucesso, lançamento de produtos, projetos de veículos automotores, gestão do produto, fatores humanos e tecnológicos da competitividade.

\section{Automobile project management: critical success factors in product start-up}

\begin{abstract}
While developing a vehicle project, it is necessary to identify its start-up critical success factors. This research is intended to validate the factors identified through Porter's prognostics for new product launching and/or through studies from Daniel and Rockart for the American automotive industry along the years 60-80. The theoretical referential used in this research were Rockart's critical success factors, and Porter's life cycle model. Having the existing literature about the subject and prognostic deductions as start points for this study, five critical success factors have been identified and validated through research and a questionnaire applied in two automaker plants in the Southern State of Rio de Janeiro, Brazil.
\end{abstract}

Key words

Critical success factors, product launch, automotive vehicle projects, product management, human and technological factors of competitiveness. 


\section{INTRODUĈ̣̃O}

A indústria automobilística é um setor de grande impacto mundial. A cada ano, cerca de 60 milhões de veículos são produzidos no mundo (OICA, 2004), consumindo para isso mais de um trilhão de dólares e empregando cerca de quatro milhões de trabalhadores de produção direta e cerca de 16 milhões envolvidos em autopeças, vendas e serviços em todo o mundo (ARBIX \& VEIGA, 2003). Especificamente no Brasil, com um total de 48 fábricas, ela representa 13,5\% do PIB industrial, gerando 92 mil empregos diretos e com capacidade de produção de 3,2 milhões de veículos por ano (ANFAVEA, 2005) - resultados significativos para um país de industrialização recente.

Com isso, as decisões do setor automotivo quase sempre tocam nos alicerces das economias nacionais e regionais, interferindo no crescimento econômico, no comércio internacional, na mudança tecnológica, nas exportações, no emprego e na distribuição de renda. Conforme Alvarez, Proença e Andérez (2002), a fabricação automotiva foi responsável pela evolução dos sistemas de produção: as formas pelas quais se organizaram a produção e o trabalho humano passam necessariamente pelo eixo central do desenvolvimento dessa indústria, desde a introdução por Henry Ford das esteiras rolantes e postos de trabalho, com tarefas, partes e ferramentas repetitivas, dando início à produção em série (QUINTELLA, 2000), passando pela produção enxuta e just in time da Toyota (CORREA, 2004).

Alvarez, Proença e Andérez (2002) citam que o Brasil possui hoje unidades de produção de todos os principais fabricantes de automóveis, sendo o país com maior diversidade de marcas de automóveis produzidas no mundo. Conforme Corrêa (2004), o Brasil ocupa a posição de $12^{\circ}$ maior produtor de veículos do mundo e, ainda que com a ociosidade atual de quase $40 \%, 1,3$ milhão de empregos são gerados em toda a cadeia produtiva, em 200.000 empresas que atuam no setor - de montadoras a lojas de autopeças. Alvarez, Proença e Andérez (2002) identificaram algumas características e tendências para este setor, das quais se destacam:

- Comparativamente aos índices de motorização de outras nações, o Brasil apresenta um potencial grande de desenvolvimento da produção automotiva;

- Há um forte incremento da capacidade de montagem nos anos recentes, com agregação de cerca de 1.000 .000 de unidades de autoveículos desde meados da década passada;

- A inserção internacional se dá basicamente no contexto regional;

- A competição se acirrou com o ingresso no mercado de um conjunto de novas marcas e fabricantes internacionais;

- É provável que diferentes iniciativas sejam dirigidas à recuperação e ao desenvolvimento do mercado local e das exportações;

- Aceleração do ritmo de introdução de novos modelos pelas montadoras - $\mathrm{o}$ aumento da variedade de produtos é uma forma de ocupar novos nichos e de competir em mercados de crescimento lento;

- Crescimento do conteúdo tecnológico agregado aos veículos - com investimentos de P\&D, especialmente nos itens de segurança, eletrônica embarcada, climatização, etc.;

- Pressão crescente por menores preços - causada pela competição nos mercados, tanto no plano global com nos mercados regionais emergentes;

- Globalização do fornecimento - como forma de viabilizar o ganho de escala na produção de componentes e subconjuntos; e

- Repasse de atividades de projeto aos fornecedores, por conta da crescente terceirização, modularização e especialização em alguns segmentos.

O desenvolvimento de novos produtos, sejam eles automotivos ou de qualquer outro segmento, é complexo, envolvendo diversas etapas que devem ser planejadas, implementadas e controladas de forma a minimizar os riscos de insucesso e, portanto, conforme Baxter (2003), deve ser baseado em informações consistentes e objetivos claramente definidos, os quais envolvem diversos interesses e habilidades.

\section{A identificação dos chamados fatores críticos de sucesso no lançamento de veículos automotores} é extremamente importante.
A importância de se estudar o setor automotivo prende-se não somente ao seu peso econômico, mas a sua grande força difusora dentro do processo de inovação, pois este é um setor que recebe e transmite inovações tecnológicas e organizacionais em relação aos demais setores industriais.

Além disso, um aspecto fundamental, dentro desse quadro de mudanças amplas do setor que abordaremos, é o papel da atividade de projeto no sucesso tecnológico e organizacional. Hoje, diante de situações inovadoras, como a introdução de novas tecnologias de processo, de produto ou de novos materiais, as empresas aprendem e ensinam novas formas de orga- 
nizar sua produção. E, neste contexto, a contribuição para o sucesso da empresa no ambiente de competição atual é decisiva.

\section{Formulação da situação-problema e questão da pesquisa}

A aceleração da competitividade mundial, alavancada pela globalização da economia de mercado, instabilidade da conjuntura econômica nacional e internacional e pelo acentuado processo de fusão de empresas que atuam no segmento de veículos automotores, levou a um novo equilíbrio entre as cinco forças definidas por Porter (1986), que regulam o mercado; além da redefinição do papel dos principais atores que atuam no setor automotivo (ROCHA, 2005).

Assim, nesse ambiente no qual se encontra a indústria automobilística, torna-se essencial, para que o desenvolvimento dos projetos nessa indústria ocorra de maneira eficaz, identificar e validar os fatores que são críticos para o sucesso no start-up de veículos automotores, na visão dos executivos das montadoras.

Como resposta a essa necessidade, surge a seguinte questão: Quais são os fatores críticos de sucesso de startup de veículos automotores?

\section{Premissas}

Para a realização da pesquisa foram adotadas as seguintes premissas:

1. Os Fatores Críticos de Sucesso (FCS) são um instrumento empírico válido para o planejamento estratégico empresarial;

2. O modelo do ciclo de vida do produto e seus prognósticos para as diversas fases são aplicáveis ao processo de lançamento (start-up) de veículos automotores;

3. Os FCS decorrentes do emprego do método de Porter (1986) são compatíveis com os FCS decorrentes do emprego do método de Rockart e da Análise SWOT.

\section{Hipóteses e questões da pesquisa}

Foram desenvolvidas, a partir dos prognósticos propostos de Porter (1986) e dos estudos de Daniel (1961) e Rockart (1979), três hipóteses como soluções provisórias para o problema, buscando identificar os fatores críticos de sucesso no lançamento de veículos automotores:

Hipótese I: Os FCS para indústria automotiva americana, definidos por Daniel e Rockart nos anos 1960-80 são válidos para o momento atual da indústria automotiva nacional.

Questões-chave:

A imagem do produto (qualidade, eficiência e estilo) é um FCS no lançamento de novos veículos automotores? Uma organização eficiente de concessionárias é um FCS no lançamento de novos veículos automotores?

Um severo controle de custos de manufatura é um FCS no lançamento de novos veículos automotores?

Hipótese II: Estratégias de Marketing com foco na percepção de valor pelos consumidores (estilo, imagem e organização eficiente de concessionárias) é um FCS no lançamento de novos veículos automotores.

Questão-chave:

Estratégias de Marketing com foco na percepção de valor pelos consumidores é um FCS no lançamento de novos veículos automotores?

Hipótese III: Um método adequado para o desenvolvimento de produtos, com a utilização das melhores práticas para excelência em custos, qualidade e prazo e que possa capturar as necessidades dos consumidores, para que estas sejam atendidas via o produto oferecido, é um FCS no lançamento de novos veículos automotores.

\section{Questão-chave:}

Um método adequado para o desenvolvimento de produtos, com a utilização das melhores práticas para excelência em custos, qualidade e prazo, e que possa capturar as necessidades dos consumidores, para que estas sejam atendidas via o produto oferecido, é um FCS no lançamento de novos veículos automotores?

\section{REFERENCIAL TEÓRICO}

Os referenciais teóricos utilizados para o desenvolvimento e análise do tema nesse trabalho foram o Ciclo de Vida do Produto e Fatores Críticos de Sucesso.

\section{Ciclo de vida do produto - CVP}

O ciclo de vida do produto é tratado por diversos autores (KOTLER, 1996; PORTER, 1986; KEPPLER, 1996; e BAXTER, 2003). Partindo de alguns aspectos relevantes para as indústrias, Porter (1986) levantou os prognósticos mais comuns sobre como uma indústria se modifica no decorrer do ciclo de vida do produto. Seu conceito consiste na hipótese de que uma indústria ou produtos individuais atravessam várias fases ou estágios, definidos por pontos de modulação no índice de crescimento das vendas da indústria. Estes estágios são assim descritos:

- Introdução: onde o crescimento das vendas é lento, os investimentos são altos e os lucros, em função disso, são 
basicamente inexistentes

- Crescimento: nessa fase, há uma rápida aceitação no mercado, levando a um crescimento das vendas e dos lucros.

- Maturidade: neste estágio, o potencial de mercado já foi alcançado, portanto o crescimento das vendas diminui. Há uma tendência à estabilização ou redução dos lucros, pois novamente é necessário investir mais fortemente em marketing.

- Declínio: fase em que lucros e vendas caem, muitas vezes de forma irremediável, levando ao desaparecimento do produto.

A natureza da concorrência em cada estágio é diferente para cada setor da indústria (PORTER, 1986). A duração dos estágios varia de indústria para indústria e, conseqüentemente, também o perfil de sua curva representativa.

\section{Fatores críticos de sucesso - FCS}

Em mercado cada vez mais exigente de inovações e qualidade, a necessidade de acesso às informações relacionadas ao papel do gerente na empresa e às suas responsabilidades particulares aumenta grandemente. Uma maneira de se determinar, com grande precisão, as informações necessárias é o método dos Fatores Críticos de Sucesso - FCS. Estes definem as áreas de performance essenciais para que a organização complete sua missão. Desta forma, qualquer atividade ou iniciativa que a organização toma, deve assegurar consistente alta performance nessas áreas; caso contrário, a organização pode não completá-la (CARALLI, 2004).

Desenvolvido por Rockart (1978), o FCS é um método empírico baseado em entrevistas, que provê técnicas estruturadas passíveis de serem utilizadas por entrevistadores na identificação das prioridades gerenciais. Os resultados, que são posteriormente confrontados para verificação das interseções, poderão ser utilizados no planejamento e construção de sistemas de informação gerenciais; num sistema top-down de desdobramento: indústria, empresa, departamento e indivíduos. A maioria dos gerentes utiliza o conceito de FCS, mesmo que implicitamente. Mas, uma vez explicitados, a alocação de recursos poderá ser mais corretamente definida.

Verstraete (2000) compilou algumas definições na literatura sobre FCS, citadas a seguir:

- Hofer \& Schendel (Nota 1): Os FCS são as variáveis graças às quais a gerência pode influenciar, por sua decisão e de forma significativa, a posição de cada firma em uma indústria. Esses fatores variam geralmente de uma indústria para outra; mas, no interior de uma indústria em particular, eles derivam da interação de dois tipos de variáveis: as características econômicas e tecnológicas do setor e as armas competitivas sobre as quais diferentes firmas do setor construíram suas estratégias.

- Boynton \& Zmud (Nota 2): FCS é o nome das coisas que devem andar bem para assegurar o sucesso de uma organização ou de um gerente; as competências em que há a necessidade de atenção especial e constante para obter alta performance;

- Leidecker \& Bruno (Nota 3): FCS são as características, condições ou variáveis que, se corretamente seguidas, mantidas e geradas, podem ter um impacto significativo sobre o sucesso de uma firma de um determinado setor;

- Bouquin (Nota 4): chamado FCS é tudo sobre o que a empresa conta para atingir seus objetivos de longo prazo de resistir às forças do setor investigado (as cinco forças da tipologia de Porter) para ser competitiva em seu grupo estratégico e não submeter-se à concorrência de outros grupos. Ou, ao contrário, se viável, preparar a passagem para um outro grupo. Os FCS podem aparecer de duas formas:

1) Barreiras que conferem à empresa uma vantagem competitiva; e

2) Performances críticas que, sem dar à empresa uma vantagem distinta, lhe permitem propor uma oferta genérica de resultados conforme seus objetivos, performance tal que, sua insuficiência ou sua degradação levará à eliminação da firma ou comprometimento de sua posição.

- Kœnig (Nota 5): Elementos constituintes do êxito em um setor, durante um período de sua história.

- Atamer \& Calori (Nota 6): Um FCS é um elemento de oferta que tem valor para os clientes (usuários, distribuidores, especificadores) e um conhecimento e/ou vantagem de custo essencial em uma cadeia de concepção produção - e distribuição do produto (ou serviço), que permite criar uma vantagem competitiva.

- Stratégor (Nota 7): Elementos sobre os quais se fundamenta prioritariamente a concorrência, correspondente às competências que é necessário controlar para ter performance.

Conforme Forster \& Rockart (1989), o conceito de fatores críticos de sucesso é utilizado há muito tempo: Aristóteles expressou a idéia de que os líderes deviam criar poucas e simples metas para suas organizações; e ressaltou que as organizações que assim o fizeram obtiveram melhores resultados do que as que não o fizeram. Da mesma forma, o Barão Von Clausewitz, escrevendo ao staff sobre os princípios da guerra, definiu um deles como sendo a "concentração de forças": segundo ele, os "maus generais" pulverizavam suas forças pelo campo de batalha, enquanto os "bons generais", de forma a garantir a vitória, concentravam suas forças nas poucas batalhas 
críticas que precisavam ser vencidas. Forster \& Rockart (1989) citam ainda que Peter Drucker, no início da década de 70, em seu livro The Effective Executive, citava que os executivos de sucesso focavam seu tempo e energia num pequeno número de problemas críticos ou oportunidades.

Desde 1979, com a publicação do artigo Chief Executives Define Their Own Data Needs, por Rockart, um grande número de artigos e publicações surgiu sobre o método dos FCS. Em 1989, Forster \& Rockart reportavam mais de 200 papers publicados referentes ao assunto, com o conceito e usos dos FCS sendo explorados e expandidos de diversas formas.

\section{conceito de fatores críticos de sucesso é utilizado há muito tempo.}

Rockart (1979) cita que os FCS estão relacionados às situações particulares de cada gerente, e que certamente irão diferir de um gerente para outro, de acordo com a sua localização na hierarquia da organização. Os FCS também podem variar com mudanças no ambiente da indústria, ou com problemas ou oportunidades de cada gerente. Os FCS não são um conjunto padrão de medidas, algumas vezes chamado de "indicadores-chave", que podem ser aplicados em todas as divisões da empresa. Ao contrário, os FCS são áreas de maior importância para um gerente em particular, de uma determinada divisão da empresa, em um determinado período no tempo.

Os aspectos e prognósticos levantados por Porter servem como balizadores para o método de Rockart, uma vez que podemos deduzir previamente um conjunto de FCS a partir dos prognósticos, e validá-los empiricamente, através de entrevistas e/ou questionários.

Fatores Críticos de Sucesso na Indústria Automotiva

Daniel (1961), apud Rockart (1978) identificou "estilo", "uma organização eficiente de concessionárias" e "severo controle de custos de manufatura" como sendo os fatores críticos de sucesso da indústria automotiva americana. Rockart (1978) adicionou a esses fatores, a adequação à regulamentação de consumo de energia. Bullen \& Rockart (1981) utilizaram "imagem", no lugar de "estilo" nos fatores críticos de sucesso da mesma indústria. A explicação está na idéia da temporalidade dos FCS - fatores temporais - que são motivados por alterações econômicas, políticas, sociais ou de condições competitivas como um todo:

- O estilo era um fator crítico de sucesso no início dos anos 1960 para toda e qualquer companhia da indústria automotiva. Conforme Bullen \& Rockart (1981), os america- nos sempre foram altamente influenciados pelo estilo, na decisão de compra de automóveis;

- Os representantes diretos dos fabricantes de automóveis com os clientes sempre foram as concessionárias. Não somente a venda inicial dependia fortemente da qualidade dos mesmos, mas também os contatos seguintes via serviços, num constante reforço de relacionamento, afetando as futuras compras de automóveis pelos clientes;

- Conforme Daniel (1961), apud Bullen \& Rockart (1981), como o preço era ditado primeiramente pela competição, o lucro por veículo - e, conseqüentemente os ganhos de cada companhia - tem forte influência do controle de custos: quanto mais eficiente a produção e a linha de montagem, maiores os ganhos;

- Em 1976/77, a adequação à regulamentação de consumo de energia tornou-se FCS na indústria, por conta dos padrões governamentais impostos para controle de poluição;

- Após o impacto inicial da crise do petróleo em 1973/74, o consumidor americano voltou a ser atraído pelos automóveis de grande porte: conforme Bullen \& Rockart (1981), enquanto as fábricas de compactos da Ford, da GM e da Chrysler eram fechadas em 1976/77, as que produziam veículos maiores dobravam os turnos de produção, de forma a acompanhar a demanda. Essa situação se reverteu quando, em 1978, ocorreu a segunda crise do petróleo, levando a maioria dos consumidores a ver seus automóveis como um meio eficiente de transporte e não mais como algo que projetasse, através do estilo, a personalidade do proprietário. A partir dos anos 1980, a "imagem" passou a substituir o "estilo" nos FCS da indústria automotiva americana: procurando manter e fortalecer a imagem de qualidade e eficiência de combustíveis, os fabricantes americanos passaram também a buscar passar a imagem de eficiência e confiabilidade, que era percebida pelos consumidores somente nos veículos importados. A imagem agora passada combinava eficiência, confiabilidade, facilidade de manutenção e patriotismo (BULLEN \& ROCKART, 1981).

\section{METODOLOGIA}

\section{Método de abordagem}

No presente trabalho foi adotado o método hipotéticodedutivo, no qual a percepção de uma lacuna nos conhecimentos, acerca da qual se formulam as hipóteses, é seguida pelo processo de inferência dedutiva, testando-se a predição da ocorrência de fenômenos abrangidos pela hipótese. Desta forma, foram desenvolvidas hipóteses como solução provisória para o problema, as quais foram testadas por meio da coleta de informações em pesquisa de campo e análise estatística dos resultados obtidos. 


\section{População / universo e amostra}

Adotou-se como universo da presente pesquisa aquele formado pelas empresas de veículos automotores instaladas no Brasil, que tenham atividades de manufatura em território nacional (montadoras). Para a obtenção de um estudo completo sobre o problema apresentado neste trabalho, seria necessário fazer a pesquisa em todo o território nacional, cobrindo diversas empresas. Devido às restrições de tempo, custo e número de pessoas envolvidas, delimitou-se a pesquisa às montadoras instaladas na região Sul Fluminense.

Para responder à pesquisa foi escolhida uma empresa voltada para o segmento de automóveis e outra para o segmento de veículos comerciais (caminhões e ônibus). Realizou-se a coleta de dados, através de questionários direcionados a gerentes e supervisores do corpo técnico de Marketing, Produto, Logística, Suprimentos e Manufatura das montadoras citadas.

\section{Coleta de dados}

A coleta de dados nesta pesquisa foi realizada por meio da aplicação de questionários compostos de quatro blocos de perguntas, que buscavam identificar e validar os FCS no lançamento de veículos automotores. Os mesmos foram enviados - após contato prévio - e as respostas foram recebidas através de $e$-mail. Todos os participantes foram informados, durante o contato, sobre a característica científica e acadêmica da pesquisa e de seu propósito.

Uma das escalas escolhidas para o instrumento de coleta de dados desta pesquisa foi a escala de comparação pareada, na qual os respondentes são solicitados a comparar dois objetos de cada vez em um conjunto de vários objetos. Tal instrumento foi utilizado para prover um seqüenciamento nos FCS deduzidos a partir dos prognósticos de Porter (1986) e dos estudos de Daniel (1961), apud Rockart (1978).

Foi também utilizada uma pergunta com resposta de escolha múltipla para avaliar a rejeição dos respondentes aos FCS apresentados como opções. Considerou-se como critério para rejeição de qualquer FCS o patamar de $30 \%$ dos respondentes, de acordo com outros estudos de validação de FCS (TOLEDO, 2000; SIQUARA, 2003).

Outra escala escolhida para o instrumento desta pesquisa foi a escala somatória ou escala Likert, que é uma escala indireta, proposta por Rensis Likert em 1932 (MATTAR, 1996), que compreende uma série de afirmações relacionadas com o objeto pesquisado: os respondentes foram solicitados não só a concordar ou discordar das afirmações, mas também a informar qual seu grau de concordância/discordância numa escala numérica.

\section{Tratamento e análise dos dados}

Após a elaboração das hipóteses nulas, o próximo passo proposto por Mattar (1996) para validação das hipóteses é a seleção do teste estatístico adequado à situação. Nesta pesquisa, como não havia conhecimento sobre os parâmetros da população, a escolha recaiu sobre os métodos não-paramétricos.

Com base nas escalas de medição utilizadas para os dados (ordinais) e o número de amostras e o seu relacionamento, utilizou-se o teste Kolmogorov-Smirnov, sugerido por Mattar (1996, p. 93), para tal situação, por "tirar proveito da natureza ordinal da informação" e por não exigir freqüências mínimas. Buscou-se, por meio deste teste, verificar se existe diferenciação entre os fatores críticos de sucesso identificados nos trabalhos de Daniel (1961), apud Rockart (1978), e nos prognósticos de Porter (1986).

s decisões do setor automotivo quase sempre tocam nos alicerces

\section{economias nacionais e regionais.}

\section{Limitações do método}

Há a possibilidade de respostas distorcidas, causadas pelo grau de motivação do entrevistado, preocupação em não transmitir uma avaliação ruim (de si próprio ou de sua empresa), a falta de conhecimentos sobre o assunto pesquisado, assim como, a inadequação do questionário (excessivo número de perguntas, escala utilizada e tempo, entre outros). Também, o entrevistador exerce influência sobre as respostas dos entrevistados, que pode ter influenciado no comportamento dos respondentes.

\section{ANÁLISE E DISCUSSÃO DOS RESULTADOS}

\section{Tabulação dos dados}

A tabulação consistiu de quatro etapas distintas:

- Contagem da frequiência com que cada um dos cinco Fatores Críticos de Sucesso foi escolhido como o mais importante em cada par das dez combinações possíveis;

- Contagem da frequiência de percepção de cada fator como não crítico; como resultado da rejeição pelos respondentes;

- Elaboração de uma lista de sugestões de Fatores Críticos de Sucesso adicionais pela percepção dos respondentes; e

- Contagem da frequiência das notas atribuídas (grau de concordância) a cada FCS apresentado e consolidação dos resultados - esta questão foi formulada com o objetivo de verificar a consistência das respostas dadas na $1^{\text {a }}$ questão: enquanto nesta os fatores foram apresentados explicitamente aos respondentes para priorização, na últi- 
ma, os fatores são apresentados de forma subjetiva, por meio de assertivas relacionadas a cada FCS.

O resultado da tabulação dos dados das questões $n^{\circ} 1 \mathrm{e}$ $\mathrm{n}^{\circ} 4$ do questionário, que buscavam identificar os FCS e sua priorização por parte dos respondentes, é apresentado nas Tabelas 1 e 2, respectivamente. Na primeira, estão apresentados o número total de pontos obtidos por cada FCS numa escala comparativa e sua participação percentual com relação ao número máximo possível de pontos dentro de cada grupo, enquanto a segunda indica o total de pontos de cada FCS, computado pelo grau de concordância com a criticidade do fator no sucesso para o lançamento de veículos automotores.

$\mathrm{Na}$ questão $\mathrm{n}^{\mathrm{o}}$ 2, que verificou a rejeição dos respondentes a algum(ns) dos FCS sugeridos no questionário, foi feita a contagem do número de vezes que cada FCS foi rejeitado e calculado o percentual de rejeições sobre o número total de elementos da amostra, conforme mostrado na Tabela 3 .

Tabela 1: Tabulação dos dados da questão no 1.

\begin{tabular}{|l|c|c|c|c|c|c|}
\hline \multicolumn{1}{|c|}{ EMPRESA } & \multicolumn{1}{|c|}{ "AUTOMÓVEIS" } & "VEICULOS COMERCIAIS" & \multicolumn{2}{c|}{ TOTAL } \\
\hline \multicolumn{1}{|c|}{$\mathbf{1}$ Imagem atrativa } & PONTOS & \% & PONTOS & \% & PONTOS & \% \\
$\mathbf{2}$ Estratégias de Marketing & 50 & $54 \%$ & 43 & $45 \%$ & 93 & $49 \%$ \\
$\mathbf{3}$ Desenvolvimento do produto & 46 & $50 \%$ & 67 & $70 \%$ & 113 & $70 \%$ \\
$\mathbf{4}$ Concessionárias & 31 & $34 \%$ & 48 & $50 \%$ & $49 \%$ \\
$\mathbf{5}$ Controle de custos & 56 & $61 \%$ & 47 & $49 \%$ & 103 & $52 \%$ \\
\hline Máximo de pontos: & 47 & $51 \%$ & 35 & $36 \%$ & $44 \%$ \\
\hline
\end{tabular}

Fonte: elaboração própria.

Tabela 2: Tabulação dos dados da questão no 4 .

\begin{tabular}{|l|c|c|c|}
\hline \multicolumn{1}{|c|}{ EMPRESA } & "AUTOMÓVEIS" & "VEICULOS COMERCIAIS" & TOTAL \\
\hline \multicolumn{1}{|c|}{ FCS } & PONTOS & PONTOS & PONTOS \\
\hline $\mathbf{1}$ Imagem atrativa & 104 & 109 & 213 \\
$\mathbf{3}$ Estratégias de Marketing & 106 & 108 & 214 \\
$\mathbf{4}$ Concessionárias & 98 & 117 & 213 \\
$\mathbf{5}$ Controle de custos & 101 & 112 & 213 \\
\hline Total de pontos: & 105 & 108 & 1068 \\
\hline
\end{tabular}

Fonte: elaboração própria.

Tabela 3: Resultados da questão no 2 - índice de rejeição dos FCS.

\begin{tabular}{|c|c|c|c|c|}
\hline \multicolumn{5}{|c|}{ NÚMERO DE SUGESTÕES DE ELIMINAÇÃO E \% } \\
\hline FCS & \multicolumn{2}{|c|}{ AUTOMÓVEIS } & \multicolumn{2}{|c|}{ VEÍCULOS COMERCIAIS } \\
\hline 1 Imagem atrativa & 3 & $13 \%$ & 1 & $4 \%$ \\
\hline 2 Estratégias de Marketing & 3 & $13 \%$ & 2 & $8 \%$ \\
\hline 3 Desenvolvimento do produto & 8 & $35 \%$ & 0 & $0 \%$ \\
\hline 4 Concessionárias & 1 & $4 \%$ & 1 & $4 \%$ \\
\hline 5 Controle de custos & 6 & $26 \%$ & 6 & $25 \%$ \\
\hline
\end{tabular}

Fonte: elaboração própria. 


\section{Método estatístico}

Os resultados obtidos na questão no 1 , que apura a ordem de priorização dos FCS segundo a visão dos respondentes, foram submetidos ao teste de Kolmogorov-Smirnov, conforme mostrado na Tabelas 4 e 5 .

Como as diferenças máximas acumuladas ( $\mathrm{D}=0,065$ para "Automóveis" e D = 0,079 para "Veículos comerciais") são inferiores aos valores críticos, com grau de significância $(\alpha=0,20)$, observa-se que não há diferenciação entre os FCS segundo a visão dos respondentes, podendo a diferença na pontuação ser atribuída ao acaso.

Os resultados obtidos na questão no 4 foram submetidos ao mesmo tratamento estatístico utilizado na questão $\mathrm{n}^{\mathrm{o}} 1$, conforme mostrado nas Tabelas 6 e 7 .

Os valores máximos de $\mathrm{D}$ nos dois casos, referentes às maiores diferenças entre a pontuação real e a teórica, mostraram-se bastante inferiores ao valor que indicaria a diferenciação entre os fatores, corroborando os resultados da questão nํำ 1 .

\section{Análise dos resultados}

A questão no 1 indicou não haver diferenciação entre os FCS: ainda que alguns FCS tenham alcançado uma pontuação superior a outros - como foi o caso do FCS "Uma Organização Eficiente de Concessionárias, Atuando ao Longo da Posse do Veículo", com 56 pontos, segundo os respondentes do segmento "automóveis", comparados com os 31 pontos de "Método Eficiente de Desenvolvimento de Produto, Utilizando as Melhores Práticas" na mesma organização - tal diferenciação não foi considerada estatisticamente representativa, podendo ser uma tendência, ou tão-somente atribuída ao acaso.

Com relação à questão $\mathrm{n}^{\mathrm{o}} 2$, que apura o índice de rejeição aos FCS deduzidos do modelo de Porter, observa-se que, considerada a amostra conjunta das organiza-

Tabela 4: Questão no 1 - Teste de Kolmogorov-Smirnov (segmento automóveis).

\begin{tabular}{|c|c|c|c|c|c|c|}
\hline FCS & $\begin{array}{l}\text { PONTUA- } \\
\text { ÇÃO } \\
\text { ABSOLUTA }\end{array}$ & $\begin{array}{l}\text { PONTUA- } \\
\text { ÇÃO } \\
\text { RELATIVA }\end{array}$ & $\begin{array}{l}\text { PONTUAÇÃOO } \\
\text { RELATIVA } \\
\text { ACUMULADA }\end{array}$ & $\begin{array}{l}\text { PONTUAÇÃO } \\
\text { RELATIVA } \\
\text { TEÓRICA }\end{array}$ & $\begin{array}{l}\text { PONTUAÇÃO } \\
\text { RELATIVA } \\
\text { ACUMULADA } \\
\text { TEÓBICA }\end{array}$ & $\begin{array}{l}\text { DIFERENÇA } \\
\text { (D) ENTRE } \\
\text { PONTUAÇÃOO } \\
\text { REAL E } \\
\text { TEÓRICA }\end{array}$ \\
\hline 4 Concessionárias & 56 & 0,243 & 0,243 & 0,200 & 0,200 & 0,043 \\
\hline 1 Imagem atrativa & 50 & 0,217 & 0,461 & 0,200 & 0,400 & 0,061 \\
\hline 5 Controle de custos & 47 & 0,204 & 0,665 & 0,200 & 0,600 & 0,065 \\
\hline 2 Estratégias de Marketing & 46 & 0,200 & 0,865 & 0,200 & 0,800 & 0,065 \\
\hline 3 Desenvolvimento de produtos & 31 & 0,135 & 1,000 & 0,200 & 1,000 & 0,000 \\
\hline Total de pontos & 230 & 1,000 & & & & \\
\hline
\end{tabular}

Fonte: elaboração própria.

Tabela 5: Questão n 1 - Teste de Kolmogorov-Smirnov (segmento veículos comerciais).

\begin{tabular}{|c|c|c|c|c|c|c|}
\hline FCS & $\begin{array}{l}\text { PONTUA- } \\
\text { ÇÃO } \\
\text { ABSOLUTA }\end{array}$ & $\begin{array}{l}\text { PONTUA- } \\
\text { ÇÄO } \\
\text { RELATIVA }\end{array}$ & $\begin{array}{l}\text { PONTUAÇÃO } \\
\text { RELATIVA } \\
\text { ACUMULADA }\end{array}$ & $\begin{array}{l}\text { PONTUAÇÃO } \\
\text { RELATIVA } \\
\text { TEÓRICA }\end{array}$ & \begin{tabular}{|c|} 
PONTUAÇÃO \\
RELATIVA \\
ACUMULADA \\
TEÓRICA
\end{tabular} & \begin{tabular}{|c} 
DIFERENÇA \\
(D) ENTRE \\
PONTUAÇÃOO \\
REAL E \\
TEÓRICA \\
\end{tabular} \\
\hline 2 Estratégias de Marketing & 67 & 0,279 & 0,279 & 0,200 & 0,200 & 0,079 \\
\hline 3 Desenvolvimento de produtos & 48 & 0,200 & 0,479 & 0,200 & 0,400 & 0,079 \\
\hline 4 Concessionárias & 47 & 0,196 & 0,675 & 0,200 & 0,600 & 0,075 \\
\hline 1 Imagem atrativa & 43 & 0,179 & 0,854 & 0,200 & 0,800 & 0,054 \\
\hline 5 Controle de custos & 35 & 0,146 & 1,000 & 0,200 & 1,000 & 0,000 \\
\hline Total de pontos & 240 & 1,000 & & & & \\
\hline
\end{tabular}

Fonte: elaboração própria. 
ções, não houve qualquer FCS rejeitado. No entanto, se observada cada amostra isoladamente, na empresa do segmento "automóveis", o FCS: "Método Eficiente de Desenvolvimento de Produto, Utilizando as Melhores Práticas" - foi rejeitado por $35 \%$ dos respondentes, índice este considerado significativo neste e em outros estudos desta natureza (TOLEDO, 2000; SIQUARA, 2003). Na empresa do segmento "veículos comerciais" não houve qualquer FCS rejeitado, sendo "Um Severo Controle de Custos de Manufatura do Veículo" o FCS com maior índice de rejeição - 25\% - insuficiente, portanto, para que viesse a ser rejeitado.

A questão $\mathrm{n}^{\circ} 3$, que verificava a intenção dos respondentes em acrescentar algum FCS à relação dos fatores sugeridos do questionário, teve como resultado 28 sugestões, as quais apresentaram diferenças apenas na redação e/ou estavam já implícitas em algum(ns) dos FCS deduzidos.
Na questão $\mathrm{n}$ - 4, buscou-se dar uma abordagem quantitativa aos mesmos FCS analisados na questão $\mathrm{n}^{-}{ }^{-}$. Os resultados não diferiram dos daquela questão, reforçando a não-diferenciação entre os FCS. E, da mesma forma que nesta, algumas tendências podem ser percebidas - por exemplo, o FCS "Método Eficiente de Desenvolvimento de Produto, Utilizando as Melhores Práticas" obteve a menor pontuação em ambas as perguntas para a empresa do segmento "automóveis", enquanto, "veículos comerciais", obteve altas pontuações. Mas o fato de estatisticamente não poder ser confirmada a diferenciação entre os FCS, tais tendências ou mesmo qualquer seqüenciamento / priorização dos FCS não pôde ser inferido.

Apesar de estatisticamente não ter sido confirmada a diferenciação entre os FCS, as respostas à questão no 1 colhidas na empresa do segmento "automóveis" mostraram "Concessionárias" como sendo o FCS com a segunda maior pontuação, obtendo o menor grau de rejeição na

Tabela 6: Questão no $4-$ Teste de Kolmogorov-Smirnov (segmento automóveis).

\begin{tabular}{|c|c|c|c|c|c|c|}
\hline FCS & $\begin{array}{l}\text { PONTUA- } \\
\text { ÇÃO } \\
\text { ABSOLUTA }\end{array}$ & $\begin{array}{l}\text { PONTUA- } \\
\text { ÇÃO } \\
\text { RELATIVA }\end{array}$ & $\begin{array}{l}\text { PONTUAÇÃO } \\
\text { RELATIVA } \\
\text { ACUMULADA }\end{array}$ & $\begin{array}{l}\text { PONTUAÇÄO } \\
\text { RELATIVA } \\
\text { TEÓRICA }\end{array}$ & $\begin{array}{l}\text { PONTUAÇÃO } \\
\text { RELATIVA } \\
\text { ACUMULADA } \\
\text { TEÓRICA }\end{array}$ & $\begin{array}{l}\text { DIFERENÇA } \\
\text { (D) ENTRE } \\
\text { PONTUAÇÄO } \\
\text { REAL E } \\
\text { TEÓRICA } \\
\end{array}$ \\
\hline 2 Estratégias de Marketing & 106 & 0,206 & 0,206 & 0,200 & 0,200 & 0,006 \\
\hline 5 Controle de custos & 105 & 0,204 & 0,411 & 0,200 & 0,400 & 0,011 \\
\hline 1 Imagem atrativa & 104 & 0,202 & 0,613 & 0,200 & 0,600 & 0,013 \\
\hline 4 Concessionárias & 101 & 0,196 & 0,809 & 0,200 & 0,800 & 0,009 \\
\hline 3 Desenvolvimento do produto & 98 & 0,191 & 1,000 & 0,200 & 1,000 & 0,000 \\
\hline Total de pontos & 514 & 1,000 & & & & \\
\hline
\end{tabular}

Fonte: elaboração própria.

Tabela 7: Questão $n^{\circ} 4-$ Teste de Kolmogorov-Smirnov (segmento veículos comerciais).

\begin{tabular}{|c|c|c|c|c|c|c|}
\hline FCS & $\begin{array}{l}\text { PONTUA- } \\
\text { ÇÃO } \\
\text { ABSOLUTA }\end{array}$ & $\begin{array}{l}\text { PONTUA- } \\
\text { ÇÃO } \\
\text { RELATIVA }\end{array}$ & $\begin{array}{l}\text { PONTUAÇÃO } \\
\text { RELATIVA } \\
\text { ACUMULADA }\end{array}$ & $\begin{array}{l}\text { PONTUAÇÃO } \\
\text { RELATIVA } \\
\text { TEÓRICA }\end{array}$ & $\begin{array}{l}\text { PONTUAÇÃO } \\
\text { RELATIVA } \\
\text { ACUMULADA } \\
\text { TEÓRIGA }\end{array}$ & $\begin{array}{l}\text { DIFERENÇA } \\
\text { (D) ENTRE } \\
\text { PONTUAÇÄO } \\
\text { REAL E } \\
\text { TEÓRICA }\end{array}$ \\
\hline 3 Desenvolvimento do produto & 117 & 0,211 & 0,211 & 0,200 & 0,200 & 0,011 \\
\hline 4 Concessionárias & 112 & 0,202 & 0,413 & 0,200 & 0,400 & 0,013 \\
\hline 1 Imagem atrativa & 109 & 0,197 & 0,610 & 0,200 & 0,600 & 0,010 \\
\hline 2 Estratégias de Marketing & 108 & 0,195 & 0,805 & 0,200 & 0,800 & 0,005 \\
\hline 5 Controle de custos & 108 & 0,195 & 1,000 & 0,200 & 1,000 & 0,000 \\
\hline Total de pontos & 554 & 1,000 & & & & \\
\hline
\end{tabular}

Fonte: elaboração própria. 
questão no 2. Da mesma forma, o FCS "Desenvolvimento do Produto", com a menor pontuação na questão n⿳o 1 , foi o FCS com maior rejeição na questão no $2(35 \%$ dos respondentes). Quanto à empresa do segmento "veículos comerciais", o FCS "Controle de Custos", com a menor pontuação na questão no 1 , foi também o de maior rejeição na questão $\mathrm{n}^{\mathrm{o}} 2$, com $25 \%$ dos respondentes.

A comparação dos resultados da análise desta questão frente às questões no 1 e no 4 mostra algumas correlações - mesmo que, conforme dito anteriormente, não encontre respaldo ou validação estatística: na empresa do segmento "automóveis", o FCS "Desenvolvimento de Produtos" - que obteve a menor pontuação na questão no 1 e a maior rejeição na questão $\mathrm{n}^{\mathrm{o}} 2$ - foi o que obteve também a menor pontuação na questão no ${ }^{-4}$. Já na empresa do segmento "veículos comerciais", o FCS "Controle de Custos", que obteve a menor pontuação na questão $\mathrm{n}^{\circ} 1 \mathrm{e}$ a maior rejeição na questão $\mathrm{n}-2$, obteve a menor pontua-

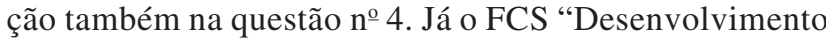
de Produtos" que, para "veículos comerciais", obteve a segunda maior pontuação na questão $\mathrm{n}^{-} 1$ e não foi rejeitada por qualquer dos respondentes desta organização, obteve a maior pontuação na questão $\mathrm{n}^{\mathrm{o}} 4$.

\section{CONCLUSÕES E RECOMENDAC̣̃̃ES}

Com base nas premissas listadas anteriormente e nos resultados da pesquisa executada, puderam-se estabelecer as seguintes análises quanto ao problema da pesquisa, hipóteses utilizadas e conclusões:

\section{Solução do problema}

O problema foi formulado da seguinte forma: Quais são os Fatores Críticos de Sucesso de start-up de veículos automotores e qual o nível de qualidade dos métodos de desenvolvimento de produtos utilizados?

Após análise estatística dos resultados obtidos em cada questão do questionário, concluiu-se que apenas quatro dos cinco Fatores Críticos de Sucesso de start-up de veículos automotores, deduzidos dos prognósticos de Porter para as diferentes fases do ciclo de vida de um produto e dos estudos de Daniel (1961), apud Rockart (1978) e Bullen \& Rockart (1981), foram aceitos para a empresa do segmento "automóveis". Para "veículos comerciais", os cinco FCS foram validados. Desta forma, a resposta ao problema pôde ser formulada como:

- Os Fatores Críticos de Sucesso de start-up de veículos automotores são:
- Uma Imagem Atrativa do Veículo, seja ela de Eficiência, Qualidade, Estilo ou Similares;

- Estratégias de Marketing com Foco na Percepção de Valor pelo Cliente no Veículo;

- Uma Organização Eficiente de Concessionárias, Atuando ao Longo da Posse do Veículo; e

- Um Severo Controle de Custos na Manufatura do Veículo.

Além destes, outro Fator Crítico de Sucesso foi identificado para esta indústria, especificamente no nicho de caminhões e ônibus, qual seja:

- Método Eficiente de Desenvolvimento de Produto, Utilizando as Melhores Práticas.

\section{Verificação das hipóteses}

A metodologia aplicada se baseia no teste de falseabilidade das hipóteses levantadas, por meio do método da hipótese nula, ou seja, pela aplicação de teste adequado à natureza das variáveis e da amostra analisada, de forma a verificar-se o grau de significância dos resultados obtidos.

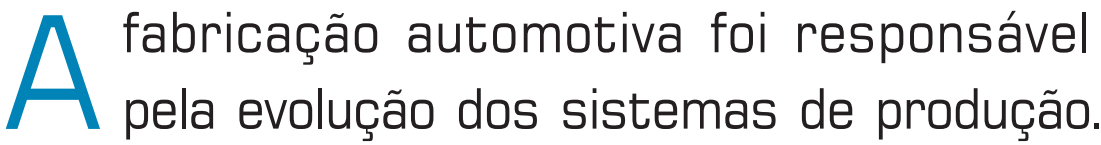

Aplicando-se o teste adequado à natureza das variáveis e da amostra, pôde-se analisar, validando total ou parcialmente ou ainda refutando, cada hipótese levantada, além de responder às questões-chave associadas, conforme mostrado a seguir:

\section{Hipótese I:}

Os Fatores Críticos de Sucesso para a indústria americana, definidos por Daniel e Rockart nos anos 1960-80 são válidos para o momento atual da indústria automotiva nacional.

Pelos resultados obtidos, podemos concluir que a Hipótese I foi considerada plausível, pois os três Fatores Críticos de Sucesso definidos por Daniel e Rockart nos anos 1960-80 foram validados pelos respondentes do segmento industrial que tem como processo crítico o lançamento de veículos automotores.

\section{Questões-chave:}

a) A imagem do produto (qualidade, eficiência e estilo) é um fator crítico de sucesso na lançamento de novos veículos automotores?

Resposta: Sim, a imagem do produto foi validada como fator crítico de sucesso no lançamento de veículos automotores em ambas as organizações pesquisadas. 
b) Uma organização eficiente de concessionárias é um fator crítico de sucesso na lançamento de novos veículos automotores?

Resposta: Sim, uma organização eficiente de concessionárias foi validada como fator crítico de sucesso no lançamento de veículos automotores em ambas as organizações pesquisadas.

c) Um severo controle de custos de manufatura é um fator crítico de sucesso na lançamento de novos veículos automotores?

Resposta: Sim, validou-se um severo controle de custos de manufatura como um fator crítico de sucesso no lançamento de veículos automotores em ambas as organizações pesquisadas.

\section{Hipótese II:}

Estratégias de Marketing com foco na percepção de valor pelos consumidores (estilo, imagem e organização eficiente de concessionárias) é um fator crítico de sucesso no lançamento de novos veículos automotores.

Pelos resultados obtidos, pôde-se concluir que a Hipótese II foi considerada plausível, pois este fator, deduzido a partir dos prognósticos de Porter (1986) no modelo de ciclo de vida de produto para análise estratégica de indústrias na fase de start-up, foi validado pelos respondentes como sendo crítico para o sucesso no lançamento de veículos automotores.

\section{Questão-chave:}

Estratégias de Marketing com foco na percepção de valor pelos consumidores é um fator crítico de sucesso no lançamento de novos veículos automotores?

Resposta: Sim, estratégias de marketing com foco na percepção de valor pelos consumidores foi validada como fator crítico de sucesso no lançamento de veículos automotores em ambas as organizações pesquisadas.

\section{Hipótese III:}

Um método adequado para o desenvolvimento de produtos, com a utilização das melhores práticas para excelência em custos, qualidade e prazo, e que possa capturar as necessidades dos consumidores, para que estas sejam atendidas via o produto oferecido, é um fator crítico de sucesso no lançamento de novos veículos automotores.

Pelos resultados obtidos, pôde-se concluir que a Hipótese III foi considerada parcialmente plausível, pois o Fator Crítico de Sucesso "método adequado para o desenvolvimento de produtos, com a utilização das melhores práticas para excelência em custos, qualidade e prazo, e que possa capturar as necessidades dos consumi- dores, para que estas sejam atendidas via o produto oferecido", que está diretamente relacionado a esta hipótese, foi validado pelos respondentes de somente uma das organizações pesquisadas. Este fator foi rejeitado por mais de $30 \%$ dos respondentes na outra empresa.

\section{Questões-chave:}

Um método adequado para o desenvolvimento de produtos, com a utilização das melhores práticas para excelência em custos, qualidade e prazo, e que possa capturar as necessidades dos consumidores, para que estas sejam atendidas via o produto oferecido, é um fator crítico de sucesso no lançamento de novos veículos automotores?

Resposta: Não para todas as indústrias, pois somente uma das empresas pesquisadas validou "um método adequado para o desenvolvimento de produtos, com a utilização das melhores práticas para excelência em custos, qualidade e prazo, e que possa capturar as necessidades dos consumidores, para que estas sejam atendidas via o produto oferecido" como um fator crítico de sucesso no lançamento de veículos automotores. Este fator foi rejeitado por $35 \%$ dos respondentes de uma das empresas.

Além destas questões-chave, buscou-se, na forma de validação dos fatores críticos de sucesso deduzidos dos prognósticos de Porter (1986) e dos estudos de Daniel (1961), apud Rockart (1978) e Bullen \& Rockart (1981), verificar a existência de mais algum fator crítico de sucesso no start-up de veículos automotores, por meio do questionamento ao respondentes se algum outro fator poderia ser considerado crítico para esta indústria, conforme a seguir:

Existe, na percepção dos respondentes do segmento estudado - da indústria automotiva - algum outro fator considerado como crítico de sucesso no lançamento de novos veículos automotores, além dos deduzidos dos prognósticos de Porter e dos estudos de Daniel e Rockart?

Resposta: Não, pois as sugestões de inclusão estavam, de alguma forma, inseridas nos fatores sugeridos, variando apenas na sua redação e/ou estando implícitas nestes.

\section{CONCLUSÕES}

Após a verificação de cada hipótese e resposta às questões-chave, pôde ser feita uma análise dos resultados com relação à contextualização do problema e, a partir desta análise, fazer inferências sobre as percepções dos executivos das montadoras, ou seja, do segmento em estudo. Pode-se, a partir dos resultados encontrados, 
concluir que:

- Os Fatores Críticos de Sucesso identificados corroboram a tendência de um foco cada vez maior no mercado consumidor, direcionando todas as ações e decisões da organização na identificação das necessidades deste e na exposição a este de como o produto desenvolvido pela organização tem a capacidade de satisfazer suas necessidades e anseios;

- Este fator "Método Eficiente de Desenvolvimento de Produto, Utilizando as Melhores Práticas", validado por somente uma das organizações, pode ser entendido como complementar ao outros FCS: primeiramente, um método adequado de desenvolvimento de produtos vai dar a sustentação necessária à criação e lançamento de um veículo que venha a atender aos anseios e necessidades do mercado consumidor e, desta forma, gerar a percepção de valor nestes. Este valor percebido pode ser alavancado através da Estratégia de Marketing adequada, que, além de ser um FCS, vai dar o devido destaque à imagem que o veículo tem - ou que se deseja vir a ser percebida pelo público consumidor. E o consumidor, no ato da decisão de compra, vai pesar o valor percebido contra o preço a ser pago, sendo que este preço sofre influência do custo de manufatura;

- Em relação ao fator "Um Severo Controle de Custos na Manufatura do Veículo", identifica-se que houve um grande índice de rejeição e baixa pontuação na questão $\mathrm{n}^{\mathrm{o}}$ 1, o que indica uma certa tendência à diminuta importância frente aos outros fatores, considerados críticos. Uma hipótese sobre este aspecto é a de que a contínua evolução dos meios de produção e das tecnologias envolvidas na produção em massa, além da terceirização, reduziu de tal forma o custo de manufatura dos veículos - o que levou à redução de seus preços reais aos consumidores - que o custo de manufatura passou a ser percebido como inerente a essa indústria;

- Essa pode ser uma razão válida para que este fator, junto ao do método de desenvolvimento de produtos, seja percebido de forma diferenciada pelas duas organizações: enquanto a empresa do segmento "automóveis" trabalha na identificação de modelos que atendam às necessidades do mercado brasileiro e utiliza a produção em massa e padronização como forma de alavancagem de seus resultados, restando aos consumidores poucas opções de individualização dos produtos - exceto por cores e opcionais escolhidos -, a outra empresa, voltada ao fornecimento de caminhões e ônibus, trabalha com diversas opções de fornecimento, além da diversas customizações que esse mercado exige, tornando-se muito mais próxima e óbvia a interação existente entre as necessidades dos consumidores e o produto que é desenvolvido e oferecido por esta organização.

\section{Sugestões para estudos futuros}

A pesquisa sobre Fatores Críticos de Sucesso no lançamento de novos veículos automotores não se esgota neste trabalho, havendo vários outros aspectos que são passíveis de uma investigação mais aprofundada, na forma de novas questões a serem respondidas:

- Quais são os fatores críticos de sucesso no lançamento de veículos automotores, segundo a visão dos executivos de outras montadoras instaladas no País, abrangendo outras regiões além da Sul fluminense?

- Como as organizações fazem o desdobramento hierárquico dos fatores críticos de sucesso da indústria, identificando os FCS da organização, dos departamentos e dos indivíduos? Quais os benefícios no gerenciamento estratégico das organizações pela utilização destas práticas?

- Quais as perspectivas de mudança nos fatores críticos de sucesso nessa indústria, por conta das alterações socioeconômicas e culturais no mercado brasileiro, bem como por conta da evolução tecnológica de novos materiais e política/preocupações com o meio ambiente?

- Como conciliar o investimento inicial no lançamento de novos veículos automotores com a necessidade de oferta de produtos customizados e com preços acessíveis aos clientes?

- Quais são os fatores críticos de sucesso de um processo de desenvolvimento de produtos e como os mesmos podem ser desdobrados por toda a organização, garantindo o sucesso comercial e adequado retorno dos investimentos feitos?

\section{Artigo recebido em 07/07/2005 Aprovado para publicação em 26/09/2005}

\footnotetext{
- Notas

1. Strategy Formulation: Analytical Concepts, West Publishing, 1978.

2. Autoria não presente nas referências bibliográficas do artigo, 1984.

3. Identifying and Using Critical Success Factors, Long Range Planning, 17 (1) 1984.

4. Le Contrôle de Gestion, PUF, 1994.

5. Management Stratégique, Vision, Manœuvre et Tactiques, Nathan, 1990.

7. Interréditions, 1993

6. Diagnostic et Décisions Stratégiques,

Dunod, 1993.
} 
ALVAREZ, Roberto; PROENÇA, Adriano; ANDÉREZ, Daniela. Rio Automotivo: Elementos da Realidade e Perspectivas de Desenvolvimento. Rio de Janeiro: SEBRAE/RJ, 2002.

ANFAVEA. Anuário Estatístico da Indústria Automobilística Brasileira - 2005. Associação Nacional dos Fabricantes de Veículos Automotivos, 2004. Disponível em <www.anfavea.com.br/ Anuario.htm>. Acesso em 29 junho 2005.

ARBIX, Glauco; VEIGA, João. A Distribuição de Veículos sob Fogo Cruzado Em Busca de um Novo Equilíbrio de Poder no Setor Automotivo. Federação Nacional da Distribuição de Veículos Automotores. A Hora e a Vez dos Distribuidores, 2003. Disponível em < http://fenabrave.org.br $>$. Acesso em 4 setembro 2004 .

BAXTER, Mike. Projeto de Produto: Guia Prático para o Design de Novos Produtos. 2a . Edição. São Paulo: Edgard Blüncher, 2003.

BULLEN, Christine; ROCKART, John. A Primer on Critical Success Factors. Working Paper, Alfred Sloan School of Management. Center for Information Systems Research, no. 69, 1981.
CARALLI, Richard. The Critical Success Factor Method: Establishing a Foundation for Enterprise Security Management. CMU/SEI-2004-TR-010. Software Engineering Institute, Carnegie Mellon, Jul 2004.

CORREA, Cristiane. As Dificuldades de Quem Produz Carros. Revista Exame, edição 827, ano 38, no, 19, 29 Set 2004, São Paulo: Editora Abril. Pág 92-97

FORSTER, Nancy; ROCKART, John. Critical Success Factors: An Annotated Bibliography. Working Paper no. 191. Center for Information Systems Research, Sloan School of Management. Massachusetts Institute of Technology. June 1989.

KEPPLER, Steven. Entry, Exit, Growth and Innovation over the Product Life Cycle. American Economic Review, vol 86 , no. 3, Jun 1996, pp 562-583.

KOTLER, Philip. Administração de Marketing - Análise, Planejamento, Implementação e Controle. $4^{\text {a }}$. Edição. São Paulo: Atlas, 1996
MATTAR, Fauze. Pesquisa de Marketing. 2 volumes. São Paulo: Atlas, 1996.

OICA. World Motor Vehicle Production by Country. ORGANISATION INTERNATIONALE DES CONSTRUCTEURS D'AUTOMOBILES. Disponível em <http://oica.net/htdocs Main.htm>. Acesso em 4 set 2004

PORTER, Michael. Estratégia Competitiva - Técnicas para Análise de Indústrias e da Concorrência. $7^{\text {a }}$. Edição. Rio de Janeiro: Campus, 1986.

QUINTELLA, Heitor. Inovação, Estratégia e Gestão do Produto - Gestão Total do Produto, Volume 1 - A Produção. Suma Econômica. Rio de Janeiro: Tamas, 2000

ROCHA, Henrique. Fatores Críticos de Sucesso de Start-up de Veículos e a Qualidade (CMMI) no Desenvolvimento de Produtos no Sul Fluminense. 2005, 353 f. Dissertação (Mestrado em Sistemas de Gestão). Universidade Federal Fluminense, Niterói, 2005.
ROCKART, John. A New Approach to Defining the Chief Executive's Information Needs. Working Paper no. 37. Center for Information Systems Research, Sloan School of Management. Massachusetts Institute of Technology. May 1978.

ROCKART, John. Chief Executives Define Their Own Data Needs. Harvard Business Review, vol 57, March-Apr, pp 81-83, 1979.

SIQUARA, Lúcia. Fatores Críticos de Sucesso no Lancamento de Solventes Industriais. 2003, 103 f. Dissertação (Mestrado em Administração e Desenvolvimento Empresarial). Universidade Estácio de Sá, Rio de Janeiro, 2003.

TOLEDO, Ruben. Fatores Críticos de Sucesso no start up de uma Franquia: o Caso BR Mania. 2000, $161 \mathrm{f}$. Dissertação (Mestrado em Administração e Desenvolvimento Empresarial). Universidade Estácio de Sá, Rio de Janeiro, 2000.

VERSTRAETE, Thierry. Essai de Conceptualisation de la Notion de Facteur Clé de Succès et de Facteur Stratégique de Risque. CLAEÉE - Centre Lillois d'Analyse et de Recherche sur l'Evolution des Entreprises, URA. CNRS 936, 2000.

\section{- Sobre os autores}

Heitor Luiz Murat de Meirelles Quintella, D.Sc.

Professor da Universidade Federal Fluminense, Centro Tecnológico, Escola de Engenharia.

Endereço: Rua Passo da Pátria, 156, Sala 329 - São Domingos - Niterói - RJ - 24210-240 - Brasil

Telefone: (21) 2239-0405 Ramal: 5451 Fax: (21) 2717-6390

E-mail: hquintel@unisys.com.br

Henrique Martins Rocha, M.Sc.

Universidade Federal Fluminense

Professor da Associação Educacional Dom Bosco.

Endereço: Estrada Resende Riachuelo, 2535 - Campo de Aviação - Resende - RJ - 27501-970 - Brasil

Telefone: (24) 3355-6000 Fax: (24)3354-0110

E-mail: hmartins@eng.aedb.br

\section{Manuela Fontana Alves}

Universidade Federal Fluminense

Engenheira do Produto a serviço de Volkswagen Caminhões e Ônibus

Endereço: Rodovia Presidente Dutra, km 296 - Rua Volkswagen, 100 - Resende - 27501-970 - Brasil

Telefone: (24) 3381- 1217 Fax: (24)3381-1072

E-mail: fontana@stargate.com.br 